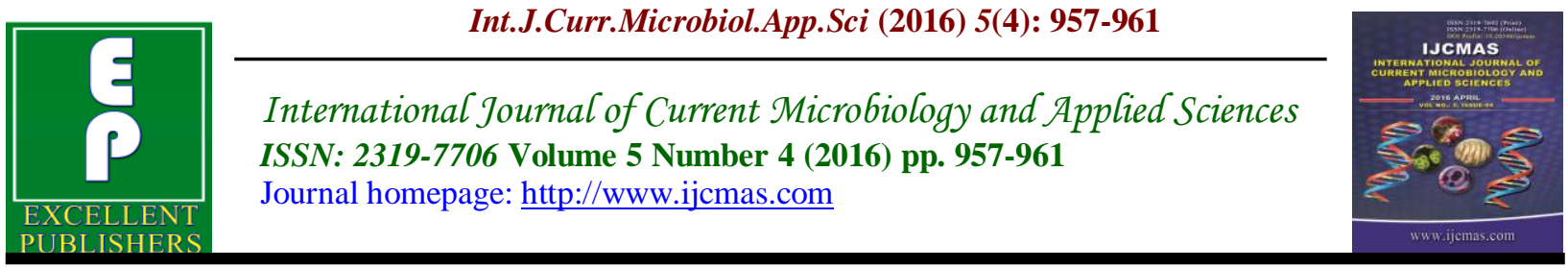

Original Research Article

http://dx.doi.org/10.20546/ijcmas.2016.504.108

\title{
Prevalence and Antifungal Susceptibility of Candida albicans in Patna, India
}

\author{
Rajiv Ranjan Prasad $^{1 *}$, Vijay Shree ${ }^{2}$, Satyendu Sagar ${ }^{1}$, Sunil Kumar $^{1}$ and Prabhat Kumar ${ }^{1}$ \\ ${ }^{1}$ Dept of Microbiology, Nalanda Medical College and Hospital, Patna, India \\ ${ }^{2}$ Dept of Community Medicine, IGIMS Patna, India \\ *Corresponding author
}

\begin{abstract}
A B S T R A C T
Keywords

Candida albicans, antifungal susceptibility test, Amphotericin B, nosocomial infection

\section{Article Info}

Accepted:

25 March 2016

Available Online:

10 April 2016

Candida species are the most common cause of opportunistic fungal infection worldwide. Candida is the major fungal pathogen of humans, causing diseases ranging from superficial mucosal infections to disseminated, systemic infections that are often life threatening. A striking feature of its pathogenicity is ability to grow in yeast, pseudohyphal and hyphal forms. The hyphal form has an important role in causing disease by invading epithelial cells and causing tissue damage. Among Candida spp., Candida albicans is the most common infectious agent. This dimorphic yeast is a commensal that colonizes skin, the gastrointestinal and the reproductive tracts. Non-C. albicans species are also emerging pathogens and can also colonize human mucocutaneous surfaces. The pathogenesis and prognosis of candidial infections are affected by the host immune status and also differ greatly according to disease presentations. This study aimed at determining the prevalence and antifungal susceptibility pattern of Candida albicans in patna and how they relate to patient's demographic data.
\end{abstract}

\section{Introduction}

With changes in the medical and surgical management of patients over the past three decades, fungi have emerged as a major cause of human disease. Of the disseminated mycoses, candidiasis remains the most prevalent, with Candida albicans causing more invasive infections than any other fungus (Elizabeth, 2009). Candidiasis or thrush is a fungal infection (mycosis) of any of the Candida species, of which $C$. albicans is the most common, also referred to as yeast infection. Candidiasis is also technically known as candidosis, moniliasis and oidiomycosis (William et al., 2006). Candida spp. are the most common cause of fungal infections leading to a range of lifethreatening invasive to non-life-threatening mucocutaneous diseases (Achkar and Fries, 2010). Candida infections can present in myriad ways. This dimorphic yeast is a commensal that colonizes skin, the gastrointestinal and the reproductive tracts. Consequently, they are also from the setting of candidiasis, albeit at a lower frequency. The pathogenesis and prognosis of candidial infections are affected by the host immune 
status and also differ greatly according to disease presentations. Therefore, diagnosis, management and treatment choices vary and need to be considered in the overall setting of the affected human host.

Due to the recognition of the increasing importance of Candida spp. as an opportunistic pathogen, an effective method is required to type the organism. Analysis of the proteins of Candida spp. can be used as a sensitive method of characterizing the yeast on the basis of their protein band profile. Keeping these facts in mind, the present study was undertaken to find out the pevalence and Antifungal susceptibility pattern of Candida albicans in superficial and deep seated infections.

\section{Materials and Methods}

The present study was conducted in the Department of Microbiology, Nalanda Medical College,Patna from mid September to mid February 2016. The cases selected for the study included symptomatic high-risk patients in whom no other aerobic pathogen was identified, and Candida spp. were isolated repeatedly in pure culture, and these infections were associated with clinical signs and symptoms of infection. Twenty nine isolates of $C$. albicans from various clinical specimens were obtained from a total of 253 patients. The isolates were identified by standard mycological methods that included colony morphology on Sabouraud's dextrose agar (SDA), germ tube test (GTT), morphology on corn meal agar (CMA) and sugar fermentation/assimilation profile (Milne, 1996). Further antifungal susceptibility testing was performed.

\section{Antifungal Susceptibility Testing}

Susceptibility testing to nystatin (100 units), clotrimazole $(10 \mu \mathrm{g})$, fluconazole $(10 \mu \mathrm{g})$ and
amphotericin-B (100units) (all from HiMedia Laboratories, Mumbai, India) was performedby the disc diffusion method(Chakrabarti et al., 1995). Candida kefyr strainY/16 was usedas control. The medium used was yeast nitrogen base glucose (YNBG) agar (HiMedia Laboratories, Mumbai, India). For susceptibilitytesting of azoles, $1.5 \% \quad$ asparagine (HiMediaLaboratories, Mumbai, India) was added to the YNBG agar. Results were interpreted as either sensitive or resistant.Antifungal susceptibility testing to voriconazole (Pfizer Inc.) was done by broth microdilution and Alamar blue colorimetricmicrodilution method. These were also used to re-test the fluconazole resistant isolates identified by the disc diffusion method. Brothmicrodilution was performed in accordance with the guidelines in NCCLS document M27- A (1997). Quality control isolates of C.albicans (ATCC 10231), C. parapsilosis (ATCC 22019) and C. krusei (ATCC 6258) were included with every test. Endpoints were determined visually by observing a colour change from blue (indicating no growth) to pink (indicating growth).

\section{Statistical Analysis}

The ' $Z$ ' test for proportion was used to compare the data. A $p$-value of $<0.05$ was taken as indicative of statistical significance, and a $p$-value of $<0.01$ was considered highlysignificant.

\section{Results and Discussion}

In the present study, 29 isolates of $C$. albicans $(11.46 \%)$ were obtained from 253 high-riskpatients, implying an isolation rate of $11.46 \%$. The age of patients in the study group ranged from newborns to $>61$ years. There was a slight female preponderance in the study population $(\mathrm{M}: \mathrm{F}$ ratio= $0.9: 1)$. The maximum number of C.albicans isolates 
were from urine (35.6\%), and cervical swabs (20.5\%). Other specimens in the study included BAL fluid, CSF, pus, sputum etc. (Fig.1). The antifungal susceptibility pattern ofthe isolates showed that all (100\%) isolates were sensitive to nystatin, amphotericin-B and voriconazole in the concentrations tested. Fluconazole resistance was observed in 7 (24.13\%) isolates (Table $1)$.

Table.1 Susceptibility Pattern of Isolates

\begin{tabular}{|l|l|l|l|}
\hline Antifungal agent & \multirow{2}{*}{ Disc potency } & No.of strains \\
\cline { 3 - 4 } & & Sensitive & Resistant \\
\hline Clotrimazole & $10 \mu \mathrm{g}$ & $27(93.11)$ & $2(6.89)$ \\
\hline Nystatin & 100 units & $29(100)$ & - \\
\hline Fluconazole & $10 \mu \mathrm{g}$ & $22(85.87)$ & $7(24.13)$ \\
\hline Amphotericin-B & 100 units & $29(100)$ & - \\
\hline Voriconazole & - & $29(100)$ & - \\
\hline
\end{tabular}

Fig.1 Isolation of C. albicans from Various Clinical Specimens

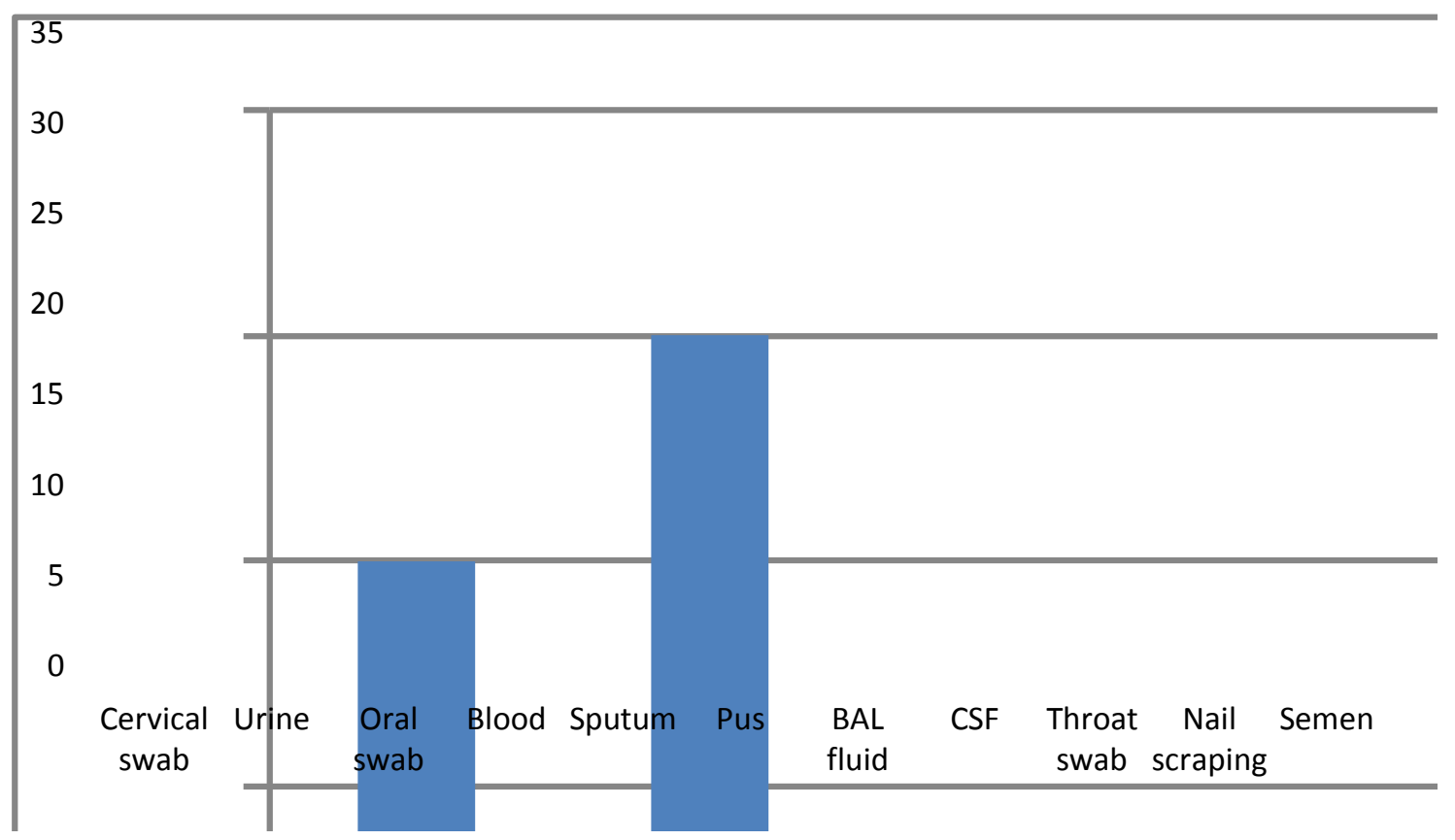

A significant increase in the incidence of fungal infections, especially those due to yeasts, particularly Candida species is being seen in recent times. This is mostly due to rising numbers of immunosuppressed patients and widespread use of broadspectrum antibiotics and steroids. Candida albicans is considered the most pathogenic member of the genus Candida and is the species most commonly isolated from clinical materials, although infections with other species of Candida have been described in recent times (Pfaller, 1996; Fadda et al., 2008). Due to the recognized importance of these agents as nosocomial and opportunistic pathogens, it is important to have a simple, effective and relevant typing method for the characterization of 
these yeasts. They have further concluded that these techniques could provide additional criteria for serologic and immunological studies of C.albicans. Antifungal susceptibility testing of our isolates revealed that all isolates were sensitive to amphotericin-B, nystatin and voriconazole. However, significant resistance $(24.13 \%)$ was observed for fluconazole. Our findings are in accordance with those of Fadda et al. (2008) who also found that there was decreased susceptibility to the older azoles among Candida albicans isolates. Similar susceptibility of C.albicans isolates was also reported by Mokaddas et al. (2007).

In conclusion, the increase of Candida infections might be related to several factors such as the:

(1) Human Immunodeficiency Virus; (ii) neutropenic persons due to anticancer treatments; (iii) the abusive use of extended spectrum antibiotics; (iv) metabolic disorders such as diabetes mellitus. The need of the hour is to understand every aspect of Candidal infections. Early and specific diagnosis is crucial and the decision to treat a patient with these unusual infections is often based on little clinical and microbiological information. Treatment decisions need careful consideration of the epidemiological factors and the immune status of the population at risk. This method can also be used in an outbreak situation or to compare different isolates to establish identity or non-identity.

\section{Acknowledgement}

The authors would like to thank the personnel of Laboratory and Faculty of Microbiology, Nalanda Medical College and Hospital,Patna for their co-operation.

\section{References}

Achkar JM, Fries BC (2010). Candida Infections of the Genitourinary Tract. Clinical. Microbiology. Reviews. pp. 253-273.

Chakrabarti A, Ghosh A, Kanta A, Kumar P, 1995. In vitro antifungal susceptibility of Candida. Indian Journal of Medical Research, 102: 13-19.

Elizabeth MJ (2009). Rare and Emerging Candida Species. Current Fungal Infection Reports. 3:152-159.

Fadda ME, Podda GS, Pisano MB, Deplano M, Cosentino S, 2008. Prevalence of Candida species in different hospital wards and their susceptibility to antifungal agents: results of a three year survey. Journal of Preventive Medicine and Hygiene, 49 (2): 6974.

Gullo A, 2009. Invasive fungal infections: the challenge continues. Drugs, 69 (Suppl 1): 65-73.

Khosravi AR, Riazipour M, Shokri H, Mousavi ML, Mahmoudi M, 2008. Characterization of the similarity of protein patterns and virulence of clinical Candida albicans isolates. Journal of Biological Sciences, 8(4): 760-766.

Kobayashi K, Suginaka H, 1984. Comparison of cell wall and membrane proteins from eight Candida species. Sabouraudia, 22: 341-344.

Laemmli UK. 1970. Cleavage of structural proteins during the assembly of the head of bacteriophage T4. Nature, 227: 680-685.

Malik A, Hasani SE, Shahid M, Khan HM, Ahmad AJ, 2003. Nosocomial Klebsiella infection in neonates in a tertiary care hospital: protein profile by SDS-PAGE and klebocin typing 
as epidemiological markers. Indian Journal of Medical Microbiology, 21: 82-86.

Malik A, Shahid M, Bhargava R, 2003. Prevalence of aspergillosis in bronchogenic carcinoma. Indian Journal of Pathology and Microbiology, 46: 507-510.

Merz WG, Connelly C, Hieter P, 1988. Variation of electrophoretic karyotypes among clinical isolates of C. albicans. Journal of Clinical Microbiology, 26:842-845.

Milne LJR, 1996. Fungi. In: Mackie \& McCartney Practical Medical Microbiology, Eds., Collee J.G.,

Fraser A.G., Marmion B.P., Simmons A., $14^{\text {th }}$ Edition, Churchill Livingstone, pp: 695-717.

Mokaddas EM, Al-Sweih NA, Khan ZU, 2007. Species distribution and antifungal susceptibility of Candida bloodstream isolates in Kuwait: a 10year study. Journal of Medical Microbiology, 56 (Pt 2): 255-259.

National Committee for Clinical Laboratory Standards, 1997. Reference method for broth dilution antifungal susceptibility testing of yeasts; approved standard. NCCLS Document M27-A.

Wayne, Pa: National Committee for Clinical Laboratory Standards, 17: 1-22.

Paul LF, Vazquez JA, Sobel JD, 1999. Candida glabrata: Review of epidemiology, pathogenesis, and clinical disease with comparison to C. albicans. Clinical Microbiology Reviews, 12: 80-96.

Peter GP, John HR, Sobel JD, Scott GF, William DJ, Timothy BG (2006). Andrews' Diseases of the Skin: clinical Dermatology. Saunders. Elsevier. 308-311.

William ED, Thomas JW, John EE, 2004. Guidelines for treatment of candidiasis. Clinical Infectious Diseases, 38: 161-189.

Pfaller MA, 1996. Nosocomial candidiasis: emerging species, reservoirs and modes of transmission. Clinical Infectious Diseases, 22 (Suppl 2): S89-S94.

Rodrigues CC, Hofling JF, Boriollo MFG, Rodrigues JAO, de Azevedo RA, Goncalves RB, Gomes LH,

Tavares FCA, 2004. SDS-PAGE and numerical analysis of Candida albicans from human oral cavity and other anatomic sites. Brazilian Journal of Microbiology, 35: 40-47.

Skrodeniene E, Dambrauskiene A, Vitkauskiene A, 2006. Susceptibility of yeast to antifungal agents in Kaunas University of Medicina Hospital. Medicina, 42: 294-9.

Sojakova M, Liptajova D, Borovsky M, Subik J, 2004. Fluconazole and itraconazole susceptibility of vaginal yeast isolates from Slovakia. Mycopathologia, 157: 163-169.

\section{How to cite this article:}

Rajiv Ranjan Prasad, Vijay Shree, Satyendu Sagar, Sunil Kumar and Prabhat Kumar. 2016. Prevalence and Antifungal Susceptibility of Candida albicans in Patna, India. Int.J.Curr.Microbiol.App.Sci.5(4): 957-961. doi: http://dx.doi.org/10.20546/ijcmas.2016.504.108 